\title{
INTERACCIONES ESTRATÉGICAS Y REACCIONES MORALES EN UNA CIUDAD MEDIA
}

\author{
Luis Alfredo Fernández Reyes ${ }^{1}$
}

\section{Presentación etnográfica}

Como casi todas las mañanas, una señora limpia la vereda de su casa en la ciudad de Salta (capital de la provincia homónima, Argentina), deseando un "buen día" a quien la mire. A unas cuantas cuadras, doña Nina, que durmió en una vereda céntrica, a unos pasos de la plaza central, se levanta y se dirige al convento Reina Madre, donde sirven desayunos a "los necesitados"; es usuaria frecuente y apenas llega es saludada por las hermanas religiosas que ya saben que vendrá.

Cerca de ahí, don Pedro levanta la estructura de cartón que armó el día anterior, se dirige a la plaza donde pasará un amigo que le hace descuento en el desayuno. Debe estar ahí temprano para no perjudicar la venta. Mientras vemos que en la vereda del frente pasa San Juan, un hombre jorobado por su problema de espalda que está pidiendo monedas a los que pasen por ahí sin disimular su problema lumbar.

A varias cuadras, frente la terminal de ómnibus El Mudo se despierta, los taxistas que trabajaron toda la noche y aún lo hacen, lo saludan. Alguien le dejó una bandeja de comida que le servirá de desayuno.

Estas cuatro personas comenzaron su día en la ciudad de Salta, aquí podemos ver estrategias demarcadas por la particularidad de la ciudad que da forma a estas interacciones y da lugar a ciertas reacciones. Dar cuenta de este entramado es el objetivo de este artículo.

\footnotetext{
${ }^{1}$ Universidad Nacional de Salta, Argentina.
} 


\section{Estado del arte}

Se hace difícil no comenzar cualquier reflexión sobre personas en situación de calle sin mencionar los brillantes trabajos de Neil Anderson y Ezra Park donde presentan al Hobo, pionero trabajador migrante que avanza con la frontera americana, personaje bohemio vinculado a la libertad y al rechazo de establecerse, y la Hobohemia, lugar donde acontece esta libertad y donde se cruzan diversos migrantes para gastar su quincena. (Anderson, 1923; Park, 1999; Hannerz, 1999). Del mismo modo, Maryse Marpsat en Francia, y Patrice Schuch en Puerto Alegre, Brasil, nos muestran como los términos Clochard y Morador de Rua designaban a estas personas con la misma carga romántica ligada más al nomadismo que a la carencia (Marpsat, 2012; Schuch, 2012). Tanto el hobo, como el clochard, como el morador de rua, acontecían en grandes ciudades producto de un proceso acelerado de urbanización y la necesidad de un trabajo ambulatorio.

No obstante, desde 1987, luego del Año Internacional de la Vivienda para las Personas Sin Hogar, promovido por la ONU, comenzaron los intentos de estimación poblacional desde un enfoque de pobreza estructural y exclusión (Turnes y Turnes, 1988), a este cambio en la representación le correspondió una modificación en los términos, y el Hobo estadounidense pasó a ser denominado Homeless, el Clochard fue sustituido por Personnes sans domicile y el Morador de Rua fue reemplazado por Pessoas em situação de rua. Argentina es partícipe de las mismas transformaciones, la noción de personas en situación de calle sustituyó al linyera, croto, ciruja, indigente y vagabundo dando cuenta de las condiciones de pobreza en términos de vivienda y desromantizando su situación. A pesar de la nueva terminología, que implicaba una nueva forma de problematización, las grandes ciudades siguieron protagonizando el escenario de reflexión de este fenómeno, como si no aconteciera en los pueblos o en las ciudades de escala mediana o pequeña.

Por ejemplo, existen diversas investigaciones enfocadas en las grandes urbes, como en Estados Unidos, en Texas City donde encontramos los trabajos de David Snow, investigando la construcción de identidad del homeless opuesta al imaginario del incapacitado mental (Snow, 1986). En Paris donde Maryse Marpsat investigó sobre las personas sin domicilio fijo y su vida entre la calle y el vestíbulo (Marpsat, 2000), en la 
misma ciudad Pascale Pichon aborda los tipos de refugio que tienen estas personas según su supervivencia y posibilidades de Servicios Sociales (Pichon, 2002) y Lois Graeff reflexionó en torno a los cuerpos como símbolo de identidad en tanto continuo mediador de relaciones sociales (Graeff, 2012). En un país vecino, encontramos las investigaciones de Pedro José Cabrera planteando una relación directa entre las teorías de la exclusión social, el fenómeno del sinhogarismo, con el consumo de alcohol y drogas aportando al proceso de exclusión en Madrid, España (Cabrera, 1998).

Ya dentro de Latinoamérica, en México DF, Libia Barajas indagó sobre la práctica del pedir como estrategia discursiva para conseguir alimentos y otros recursos (Barajas, 2012). En Brasil, Gualda Pereira en Río de Janeiro, dio cuenta de una agencia en el proceso de elección de la vestimenta y la moda; en tanto a la construcción corporal (Pereira, 2003); Marcia Nectoux y otros problematizaron el alcoholismo como patología conductual en la misma ciudad (Nectoux, 2012); en Brasilia Theresa Jardim Frazao trabajó sobre la invisibilidad de los moradores de rua en el discurso periodístico (Jardim, 2010). En Chile, Macarena Weason, en la ciudad de Santiago, ahondó en torno a la identidad y la exclusión social, articulados en la noción de reconocimiento recíproco (Weason, 2006); mientras Farré Espinoza sobre las formas de sobrevivencia y territorialización del lugar (Farré, 2011).

Para Argentina, y particularmente para Buenos Aires, Mariana Biaggio investigó la resignificación espacial de la ocupación de estas personas en el espacio público, las formas de reconocimiento entre estas personas donde existen códigos, costumbres, valores exageradamente sutiles para diferenciarse entre sí, además de ahondar en un caso de conformación de un coro en la ciudad porteña que concluyó en una colectivización para la exigencia de derechos (Baggio, 2006, 2010, 2011). En la misma ciudad, Griselda Palleres investigó el fenómeno en la resignificación del estigma que recae sobre estas personas en una serie de estrategias de supervivencia, sistematizado en circuitos de subsistencia y la sociabilización en el proceso de apropiación espacial, el desplazamiento en los circuitos y los lugares en común como por ejemplo las duchas públicas (Palleres, 2004, 2010, 2012). También en Buenos Aires, Paula Rosa indagó la relación entre las personas en situación de calle con los agentes de políticas públicas en la construcción de identidad de un "ellos" y un "nosotros" bajo el prejuicio y el estigma; y la creación de categorías por parte de los 
voluntarios para estas personas atendidas en las distintas organizaciones (Rosa, 2012, 2013). En la ciudad vecina de Rosario, Mariel Bufarini investigó sobre las disputas en la territorialización de espacios rosarinos tanto públicos como privados; logró identificar entre aquellos que viven en la calle y aquellos que viven de la calle, que en principio son confundibles pero suponen una distinción sutil, además de rechazar el concepto de desafiliación ya que ella reconoce una construcción de redes de sociabilidad que no impide un desarraigo territorial (Bufarini, 2007, 2008, 2012).

Entonces, vemos al menos una serie de investigaciones que problematizan dimensiones de la vida de estas personas, focalizadas en Chicago, Nueva York, Texas, Madrid, México DF, Rio de Janeiro, Santiago de Chile, Buenos Aires y Rosario. Sin embargo, carecemos de antecedentes que indaguen la forma de vida de estos individuos, situados en alguna ciudad de escala media. Quizás valga mencionar la excepción de la investigación de Yareani Barreat, en la ciudad venezolana de Mérida, enfocado en los individuos en un estudio psicosocial, pero que no aporta mucho a la literatura antropológica, ya que obviamente no era de su interés (Barreat, 2007), y un trabajo nuestro que será citado a lo largo del artículo haciendo las conexiones que creemos pertinente evitando repetir contenido (Fernández, 2016).

Desde las primeras investigaciones hasta las más cercanas en tiempo y espacio se realizaron en ciudades de gran tamaño, e incluso metropolitanas. Esto no implica que sus investigaciones sean inútiles para nosotros. Al contrario, podemos tomarlos como referencia y aprovechar sus indagaciones para problematizar el fenómeno en una ciudad de escala media como Salta, pero sin que ello implique que nuestro estudio sea un espejo de los ya realizados, sino más bien priorizando el fenómeno tal cual acontezca.

\section{Ciudad de Salta, "linda ciudad"}

La ciudad de Salta, ubicada en la provincia homónima al norte de Argentina, puede considerarse una ciudad de escala media. Según el censo del año 2010 tiene una población de 535 mil habitantes en una superficie de 60 kilómetros cuadrados. No obstante, como indican Silvia Boggi y Nora Galván, lo fundamental para considerar una ciudad "media" no es su dimensión o escala, sino cómo las ciudades son vividas y 
significadas a través de la experiencia de sus mismos habitantes, quienes construyen y participan de la ciudad en tanto "media" (Boggi y Galván, 2016).

Durante la década de los 90 el poder ejecutivo impulsó un proyecto para convertir esta ciudad en un destino turístico, recibiendo tanto visitantes extranjeros como del país, sobre todo de la ciudad de Buenos Aires; política eficaz que delimitó gran parte de la identidad salteña dentro y fuera de la provincia (Flores, 2001). Bajo este proyecto se comenzó a adjudicarle un adjetivo a la ciudad a fines promocionales, de ahí en más se hablaría de "Salta, La Linda". Slogan turístico que es reconocido a lo largo del país, o al menos los habitantes salteños creen que esto es así en parte de su imaginario urbano al ver sus atractivos histórico geográficos y la representación que Salta tiene dentro del país. Se establece la relación dialéctica entre los estructural y lo simbólico que Ana Silva y Silvia Boggi problematizan en ciudades medias (Silva y Boggi, 2016).

En este sentido, aquellos que vivían en la ciudad aun antes de este maquillaje pueden confirmar sus recuerdos y decir que "Salta siempre fue linda"; como nos comentaba una anciana vecina mirando una de las tantas publicidades en el centro salteño que le recuerdan al habitante que vive en un destino turístico y que debe sentirse orgulloso de ello, vemos aquí lo urbano como un objeto significacional (Gravano, 2013). No obstante, la ciudad no sólo es "linda", un lugar amigable para vivir, sino que también presenta algunas características que serán importantes para sostener nuestra propuesta.

En camino a realizar una jornada de trabajo de campo, vimos a una señora que barriendo la vereda saludaba a todos aquellos que la miraran a sus ojos deseándoles un buen día y, por su parte, los saludados respondían respetuosamente devolviendo el deseo. Mientras subíamos al colectivo que realizaba su habitual recorrido algunos pasajeros subían saludando al chofer quien respondía reconociendo a algunos que frecuentan la línea, incluso esperó el arranque ya que un usuario a lo lejos corría para alcanzarlo. En el mismo colectivo un asiento se desocupó y un joven corrió a ocuparlo, nadie dijo nada pero recibió unas cuantas miradas de desaprobación. Horas más tarde, en la plaza central vimos los primeros preparativos para la celebración de la Virgen del Milagro; faltaba un mes, pero algunos ya comenzaban la Novena, otros aprovechaban para vender rosarios. Poco después, en un parque, vendedores ambulantes de comida 
rápida armaban sus puestos de venta mientras el inspector se acercaba para decirles que en un rato pasaría el jefe, que esperaran para desarmar el puesto. El jefe sabía de toda la situación (como nos enteramos después) pero dejaba pasar la irregularidad. Estas situaciones son fragmentos de trabajo de campo que creímos no servirían de mucho, pero vemos las características del lugar donde se realizó la etnografía, Salta como ciudad media: es un lugar de renombre, existe una supremacía de ética cristiana, y presenta una arbitrariedad personal en la implementación de políticas públicas.

Por renombre entendemos algo semejante a los que Luc Bolstanski llama sobre la cité de la fama (Boltanski, 2006), como esa participación por medio de la interacción no anónima sino con presencia reconocible, donde aunque no se conozca el nombre de las personas, se infiere la identidad y lo que se espera de ella. Paralelamente, según el censo del 2010, la provincia de Salta se expresaba la más católica de todo el país, y correspondientemente en la ciudad el 90\% se declaraba Cristiano (Católico, Evangelista, Testigo de Jehová, Mormón, entre otros), mientras un 5\% era religioso no cristiano (Budista, Judío, Musulmán) y el restante 5\% no religioso (ateo, agnóstico, escéptico, $\mathrm{N} / \mathrm{C}$ ), estos datos quedan corroborados en la fuerte presencia de la religiosidad cristiana, protagonizada por el catolicismo, dentro de la ciudad en la fiesta patronal donde acontece un inconfundible hecho social total, en la cantidad de colegios secundarios y primarios religiosos, en la opinión publica tan presente que incluso afecta algunos discursos políticos en campaña, etc. Finalmente, podemos reconocer una arbitrariedad en la ejecución de políticas públicas, como casi en cualquier ciudad, pero modelada por la moral de las dos características anteriores, o sea en un reconocimiento personal y cristiano; esta arbitrariedad es fácilmente visible en los casos de tensión entre la desigualdad de género y la ética cristiana: donde un médico que tiene la orden del juez de realizarle un aborto a una joven se niega a hacerlo por sus convicciones religiosas, $\mathrm{o}$ un juez que luego de recibir las investigaciones de un femicidio niega la condena a los asesinos por considerar que la joven asesinada no se comportaba como una verdadera señorita. Aunque la arbitrariedad aparezca en su expresión máxima en esos casos

\footnotetext{
${ }^{2}$ Aquí reconocemos que existe un desfasaje en la propuesta de Bolstanski con lo que operativamente tomamos de ella, ya que su propuesta es más ambiciosa y supone un universal al cual referir la actitud moral. Aun no podemos asegurar si Salta como ciudad media presenta la cité de la fama como elemento dominante, para ello haría falta mucha más etnografía, aunque si podemos emplearla heurísticamente si nos permiten el atrevimiento.
} 
tristemente reales, aparece en otras situaciones de menor impunidad en este lugar que definimos como Salta.

Nos parece heurística la propuesta de Marc Augé, entendiendo al lugar como aquel espacio construido cotidianamente (en este caso por los ciudadanos salteños) a través de la significación de la experiencia donde se puede desarrollar la identidad, la relación y la historia (Augé, 2000). La señora que saluda a aquellos que la miren, los pasajeros del colectivo, los asistentes a la novena, el colectivero, el inspector, el jefe, participan de la moral de esta ciudad media, aún el joven que ocupa un asiento ya que en su acción recibe la desaprobación del colectivo (valga el obvio juego de palabras), aún el médico y el juez que luego fueron defendidos por un sector de la población y parte de la opinión pública.

En este sentido, entenderemos moral según la propuesta de William Thomas, como conjunto de reglas y normas que regulan la expresión de las acciones porque contienen sucesivas definiciones de la situación que adquieren valor de lo aceptado y de lo no aceptado. La definición de la situación es aquel estado de examen y deliberación necesario para definir la conducta autodeterminada internamente (Thomas, 2005). En el primer ejemplo citado la situación era el saludo cordial, una atención cortés (parafraseando la desatención cortés de Simmel en una sociedad anónima) por parte de la vecina quien propone y define la conducta del receptor, quien adopta la moral saludando (acción expresa) o revelándose frente a ella no haciéndolo (igualmente acción expresa), o sea, aceptando la definición de la situación colectiva propuesta por la señora, o imponiendo la suya individual no cediendo ante aquella. Ambos, tanto la señora como el saludado son conscientes de la situación, y deliberan su conducta.

Ahora bien, todo este lugar definido por los ciudadanos como ciudad de Salta, donde prevalece el renombre, la ética cristiana y una arbitrariedad de la ejecución de la política pública, es donde acontece la vida de las personas en situación de calle. Es necesario recordar estas tres características del lugar porque codifican la acción de estas personas. 


\section{Personas en situación de calle}

Como en casi todas las ciudades, Salta presenta en sus veredas personas que tienen el espacio público como vivienda. En este lugar estas personas deben realizar sus vidas, resolver los problemas cotidianos, establecer relaciones sociales, crear su identidad, conformar su historia. En un artículo anterior pudimos desarrollar las lógicas de emplazamiento espacial en la ciudad de Salta, interrelacionadas con la morfología de la ciudad, en tanto ciudad media, que permite distinguir dos zonas: de vigilancia y de bazar, la primera de luz y protección, la segunda de oscuridad y ocultamiento, que son territorializadas o recorridas por estas personas en búsqueda de protección o libertad, ante el peligro de vivir en la calle, ante el control policial respectivamente (Fernández, 2016). Continuaremos este trabajo problematizando las estrategias de supervivencia de las mismas personas, enfocadas en la obtención de alimento y dinero ${ }^{3}$. Aquí vale la pena convocar la diferencia planteada por Larissa Lomnitz sobre subsistencia y sobrevivencia, y su conclusión de que los marginados utilizan modalidades diferentes para sobrevivir y para subsistir. La inestabilidad de la subsistencia da una importancia de primer orden a la sobrevivencia. Si el primer aspecto respondía, en la investigación de la autora, a la inserción intersticial y precaria en la economía urbana, el segundo, que conformaba la seguridad económica correspondía a la totalidad de las relaciones sociales que aquí nos parece pertinente rescatar (Lomnitz, 1998).

Para la obtención de alimentos y dinero realizan estrategias de supervivencia, que también podría semejarse a la interacción estratégica de Erving Goffman (Goffman, 1971), considerando como plantea Thomas la rivalidad que existe entre la definición de la situación colectiva que promueve la moralidad local (como la señora que saluda) y la definición de la situación individual en búsqueda de deseos particulares (en este caso la obtención de recursos, Thomas, 2005). Estas interacciones apelan a un "portarse bien", a la lástima y a la amenaza, buscando despertar en el ciudadano reacciones morales como la simpatía, la caridad y el temor, respectivamente. Estas interacciones

\footnotetext{
${ }^{3}$ Los recursos necesarios para vivir no se reducen al alimento y la comida. También es necesario mencionar la vestimenta (vinculado a una construcción de identidad personal), los depósitos (donde se guardarán aquellos bienes de valor), los servicios (acceso a un baño, agua potable, herramientas de higiene, electricidad para cargar celulares por ejemplo, entretenimiento como un televisor o una radio, etc.), y auxilio burocrático (generalmente para conseguir un certificado y cobrar alguna pensión, o prestarse un domicilio para obtener un trabajo, etc). Dejamos fuera la obtención de estos recursos, bienes y servicios no porque sean menos importantes, sino por espacio. Esperamos trabajarlo en otro artículo.
} 
estratégicas se dan en situaciones reales, en el sentido de que los protagonistas sostienen su realidad, donde se pone en juego la moral de ciudad media a través de las acciones y reacciones de los protagonistas que comparten el lugar. Estas situaciones corresponden a los momentos en que las llamadas personas en situación de calle consiguen los recursos a través de la compra diferencial, las instituciones de ayuda, los grupos de ayuda, un contacto, la caridad personal, la práctica del pedir, la recolección directa y el robo. A continuación desarrollaremos estas situaciones para dar cuenta de las estrategias y reacciones en la interacción y, como corresponden al relato etnográfico, será escrito en tiempo pretérito no porque ya no sucedan más sino para facilitar la lectura.

\section{Comer: cinco situaciones en la ciudad media}

Existían entonces recursos que se suponen necesarios en el día a día en las calles de Salta. No importa cuántos años se estaba en esta situación, qué tan bien uno podía manejarse en el lugar, cuántos amigos o enemigos uno tenía, cuánto dinero se disponía, se consuma alcohol, drogas o no, se suponía que todos los días se hacía necesario comer. Esta suposición era relativa, puesto que algunos adultos pasaban días sin comer, por mantenerse en estado de ebriedad o los efectos de algunas drogas. Durante esos días existía una suspensión de las actividades de supervivencia, no se repetían los circuitos, no se esperaba a los grupos de ayuda, e incluso no se repetían los lugares de pernocte, ya que los tiempos de reposo y actividad estaban alterados por dichos consumos.

Ahora bien, existían por lo menos cuatro grandes situaciones donde se consigue alimento: la compra diferencial (que es la menos frecuente, contenida en el uso del dinero como medio de pago), la obtención mediante las instituciones de ayuda, los grupos de ayuda y la caridad personal de los transeúntes urbanos ${ }^{4}$.

La compra diferencial era el intercambio de comida por dinero. Poco frecuente por su elevado costo, no era la primera opción para conseguir los bienes, y venia acompañada de una búsqueda de precios muy precisa donde se aprovechaban las ofertas

\footnotetext{
${ }^{4}$ Aquí dejamos fuera el trabajo "informal” porque creemos que merece un análisis detallado y minucioso sobre todo problematizando la noción de forma, que sería imposible incluir en este artículo con precisión. Por ello lo trabajaremos en un próximo artículo evadiendo por ahora su problematización.
} 
de los distintos puestos o ferias. Este intercambio se daba generalmente en el bazar donde la "informalidad" permitía precios bajos.

Por las mañanas, don Pedro, un hombre de unos sesenta y cinco años que duerme en las puertas de un edificio público, esperaba a Marcelo, un vendedor de desayunos ambulante para comprarle a precio reducido un café o té con algunos bizcochos. En una situación parecida, don Hernán, que dormía en un callejón cerca del parque más grande la ciudad, y Ernesto, quien durmió durante meses en un hospital público detrás de la guardia, conseguían desayunos o sándwiches, de unos vendedores ambulantes, que le cobraban menos que lo que cobrarían a cualquier otro cliente (menos de la mitad del precio de venta). En ese sentido, tal intercambio, se encontraba a medio camino, por decirlo así, de una operación de compra/venta impersonal, y de una operación caritativa personal. Cuando les preguntamos a los vendedores por el precio “especial”, estos argumentaban: ese es el precio de costo, y debían cobrarlo porque ellos también necesitaban del dinero. $\mathrm{Y}$ sin embargo, esta suspensión del beneficio se generaba en el marco de un conocimiento del beneficiado y su condición por compartir el espacio en las mismas horas. Así pues, si bien parecía impersonal, al igual que cualquier transacción monetaria, estaba fuertemente personalizada. Marcelo era una amistad de don Pedro, al igual que los vendedores de don Hernán y Ernesto. Aunque esta personalización era denegada en el mismo acto por mediación del dinero (Simmel, 1977), tomando distancia de la caridad, no dejaba de ser un descuento solo para ellos, quienes a su vez mantenían la relación simpática portándose bien, por ejemplo pagando el mínimo, no abusando del beneficio.

Otra forma de obtención era mediante las instituciones de ayuda que refiere a aquellas instituciones civiles (ONG) y religiosas (conventos e Iglesias) que ofrecían servicios o bienes a aquellos (a quienes suponían "necesitados") que concurrían a sus locales (que, por lo general se hallaban distribuidos en el casco céntrico de la ciudad), proporcionaban comida, ropa, baños y/o lugares para dormir.

En la misma dirección, doña Nina, una señora de unos cincuenta años ansiosa por cobrar alguna jubilación, cargaba sus bolsas todos los mediodías para llegar a la iglesia San Alfonso donde existía un comedor que servía almuerzos a los necesitados. Ahí podía asegurarse un buen plato de comida y si sobraba, pedir un poco para la noche. Aquellas personas que conformaban el llamado grupo el pregonerito, (bautizado así por 
dormir frente a un quiosco que tiene pintado el nombre de un diario local "El Pregonero”) caminaban varias cuadras para dirigirse a la casa de doña Gloria, una mujer adventista "de gran corazón" que abría las puertas de su casa, en un barrio aledaño a por lo menos un kilómetro y medio del casco céntrico, para atender a los "hijos necesitados de Dios" (adultos y niños en situación de calle, drogadictos, locos, inválidos, etc.) y ofrecerles un plato de comida "bien cargado" como decían sus comensales. De igual manera, los días domingos podían dirigirse al centro del parque San Martín, ya que un grupo religioso se ubicaba en un monumento circular con bandejas, platos y cubiertos de plástico ofreciendo comida a quienes se acercaban.

Llegada la noche, en las puertas de la ONG Manos Abiertas ${ }^{5}$, llegaban varios visitantes que iban a ver si podían comer algo de la gran olla que se prepara para los usuarios de la hospedería, entre ellos doña Nina. La forma típica de pedir comida era apelar a la lástima, anunciarles a los voluntarios que "hace días" que no comían, o el hambre que tenían, más allá que esto fuera verdad o mentira. Más o menos a la misma hora Chacarero caminaba por los puestos de comida donde se había hecho buenos amigos, para pedir lo que hubiera sobrado del menú general, “ipodés comer asado todos los días!, el que sabe, jamás se caga de hambre" nos decía, seguro de sus facultades que hasta ese momento le había permitido comer "rico y mucho".

Estos casos, ejemplifican las formas de aprovechar las fuentes de recursos para proveerse de alimento, situaciones de interacción moral, recorriendo varias instituciones de ayuda, amistades proveedoras de comida, o algún particular caritativo. Empleamos la noción de fuente como metáfora para señalar un aprovisionamiento de recurso que es estratégicamente aprovechado. Ahora bien, en todos ellos vimos una relación amistosa con las personas involucradas en las fuentes de recursos, y un esfuerzo por mantener la naturaleza de esta relación. Creemos que aquí se establecía una relación simpática, de amistad, de confianza, entre las personas y los adultos involucrados, una relación que se mantenía en la medida que los adultos se "porten bien", o sea, no se presenten

\footnotetext{
${ }^{5}$ La ONG Manos Abiertas es una organización a nivel nacional, con sede en la provincia de Córdoba que ofrece una serie de servicios a quienes se consideran en necesidad. Para la ciudad de Salta, se ofrece la llamada Hospedería, que consiste en dar alojamiento, merienda y cena, a aquellos que no tengan un lugar donde dormir durante un tiempo máximo de seis meses, donde se supone que el usuario buscará trabajo sin tener que preocuparse por donde dormir. Asimismo para conservar el lugar éste debe colaborar con la limpieza de la hospedería, y si desea con la preparación de la merienda y cena, que está a cargo de voluntarios de distintas edades.
} 
alcoholizados a las instituciones, respeten los horarios, sean agradecidos al recibir el servicio, lleguen a horario, entre otros comportamientos.

No sólo estaba dominado por la simpatía, sino que también algunas personas apelaban a la lástima del benefactor, demostrando una legítima necesidad de pedir ese plato, esperando producir caridad. De esta manera, todas estas personas se desplazaban, para conseguir un plato de comida, un desayuno, una cena, que saciara la tensión del estómago. Y complementado el recorrido que las personas realizaban, se hallaban los recorridos de los grupos de ayuda, que también podían identificarse como civiles (fundaciones) o religioso (como parte de una actividad perteneciente a una iglesia). Se conformaban por voluntarios, en su mayoría jóvenes, quienes se organizaban para recorrer el casco céntrico ofreciendo comida a las personas, que suponían necesitados. Frecuentemente un grupo se conformaba exclusivamente para esta acción; si se quiere eran auto-convocados, sin hacer referencia a la noción en movimientos sociales, sino a una iniciativa ética o política. Realizaban recorridos estables, eran ellos los que se desplazaban por la ciudad, en contraste con las instituciones que llamaban a desplazarse.

Los grupos de ayuda se reunían en días programados de la semana (por ejemplo, todos los viernes, o martes y jueves, etc.) con el fin de "ayudar al necesitado", a través de dichos recorridos. Los recorridos eran mapas imaginarios espaciotemporales que los grupos transitaban para acercarse a las personas beneficiadas, con un punto de encuentro, puntos fijos donde detenerse, cuadras por donde pasar e incluso un punto de despedida.

Al estar programados, los potenciales beneficiarios tenían presente los días que cierto grupo pasaría, "el lunes no sale nadie, el martes a la mañana sale Rocío, a la noche los del turbante y el grupo de Jimena, el miércoles nadie, el jueves a la mañana de nuevo sale Rocío y a la noche del grupo de Jimena, el viernes salen los evangelistas y los católicos, y el sábado una pareja adulta", nos decía don Ernesto quien durmiendo en la guardia del hospital era beneficiario de todos éstos. Él, como el grupo pregonerito, y doña Nina eran comensales frecuentes de estas personas, y mantenían una relación amigable con los voluntarios a tal punto que se podían festejar cumpleaños, como el de doña Nina, quien celebró dos veces ya que dos grupos le organizaron el festejo. Pero así como con las instituciones, no sólo se acude a la simpatía, sino también a producir lástima, ya que en varias ocasiones las personas aprovechan para pedirle a un auto- 
convocado alguna prenda de ropa o una mochila argumentando su necesidad, como aquella vez que al grupo pregonerito le "robaron" el colchón donde dormían y pedían a los grupos un reemplazo recordándoles lo difícil de dormir en el piso.

La caridad personal, en oposición a la institucional y grupal, podía ser regular o azarosa, y se refiere a los actos caritativos de los transeúntes que daban comida, dinero, ante el testimonio de reconocimiento del sufrimiento. Aquel acto de caridad por parte de los transeúntes urbanos, de aquellos ciudadanos que concentrados en sus vidas cotidianas (que no se auto organizaban como los grupos de ayuda ni se ofrecían como voluntarios en las instituciones) ofrecían casi fortuitamente un plato de comida o un poco de dinero.

Así, podemos ver actos de caridad provenientes de los transeúntes anónimos. Don Pedro contaba que "cada tanto" se acercaban transeúntes, sobre todo mujeres, y sin motivo aparente le regalaban dinero, "así..., diez pesos" o un plato de comida; siempre recordaba aquella madrugada que se levantó y encontró afuera de su estructura de cartón un pernil casi entero, "sabroso", aunque nunca supo quién o quiénes fueron sus proveedores. Don Ernesto, que vivía durante semanas cerca de la guardia del hospital, también recibía ayuda anónima de aquellos que mientras visitaban a sus enfermos, a veces sin mediar palabras, se acercaban a dejarle dinero y se retiraban. Siempre, durante un año y medio, frente la terminal se instalaba para dormir aquel hombre de tercera edad, de vestimenta bastante harapienta, de cabellos y barba larga y blanca, llamado el Mudo, porque efectivamente no podía hablar; y ya que siempre estaba ahí, muchos vecinos de los departamentos o casas a pocos metros se acercaban a regalarle comida, a veces sobras de la cena, otras, bandejas enteras con cubiertos y servilletas.

En este sentido, aun cuando doña Nina estaba sentada en el hall de la escuela, y parecía no estar haciendo nada, sabía que en ese lugar podía esperar tranquila el horario para dirigirse a una calle del centro a pernoctar, sabía que estando ahí cualquier ciudadano que le naciera un gesto caritativo podía practicar la economía de la salvación dándole un poco de comida, o dinero. Sabía que era ubicable, y si consideramos que el mayor flujo de ingresos provenía de ciudadanos anónimos, convenía estar siempre en el mismo lugar rondando las mismas horas. Este momento del día que parecía ser pasivo es quizás uno de los más estables, a menos que se haya encontrado un lugar que cumpliera la misma función pero con mayor éxito. Por tanto, se permanecía en las 
mismas cuadras sentada a las mismas horas, haciendo de su presencia y paciencia un punto de reunión, un espacio de referencia ${ }^{6}$.

Estas donaciones caritativas no estaban pactadas, sino simplemente se daban, sin previo aviso, aunque fortuitas eran probables, y era por ello que el emplazamiento de don Pedro, don Eusebio, el Mudo y doña Nina (que ahora nos sirven de ejemplo) eran estratégicos, así como las lógicas de emplazamiento conforman el desplazamiento y la territorialidad (Fernández, 2016). Era la más importante de las fuentes mencionadas en cuanto a los recursos obtenidos. La centralidad de lo obtenido y su carácter azaroso podían ser contradictorios, pero en los términos de don Lito, "no sé cuánto voy a recibir de comida, pero a fin de mes, sé que es lo que más me va a dar”. Este hecho mostraba la importancia de la vida moral en el aprovisionamiento de un lugar de escala media como Salta.

En esta caridad personal vemos una actividad expresiva que pone de manifiesto la necesidad de dinero, alimento, y sobre todo en el caso de lograrse una relación prolongada, una relación simpática, ya que si las personas eran los mismos, y estos respetaban la moralidad, la situación - el portarse bien - tendían a establecerse una relación positiva entre ellos dando lugar a la cordialidad, la amistad, el respeto, la confianza, etc. De todas formas, si estas personas no eran las mismas vemos operar la lástima generando caridad personal, que concluye en regalos ya no estables sino espontáneos, lo que se tenga en la billetera, lo que sobre de la cena, etc.

Ahora bien, ninguna de las personas hasta aquí citadas hacia uso exclusivo de alguna situación, sino más bien tendían a complementarlas con una suerte de opciones, conformando un circuito de supervivencia donde podían asegurarse la obtención de comidas y prendas. Doña Nina no visitaba una institución de ayuda, sino más bien varias para así conseguir lo buscado; don Hernán no tocaba las puertas de una sola iglesia, es más bien politeísta en su recorrido y no así en sus palabras, ya que como él decía "Dios hay uno solo", aunque atendía en varios lugares. La disponibilidad de recursos aunque estaba programada no estaba asegurada, a un restaurante podía o no sobrarle comida, una iglesia podía o no abrir sus puertas, una señora caritativa podía inaugurar con entusiasmo un comedor para los necesitados en el centro de la ciudad

\footnotetext{
${ }^{6}$ De todas formas esta caridad no está dirigida únicamente a las adultos en situación de calle, sino también a niños de la calle, aquellos considerados locos, mendigantes, discapacitados (términos despectivos), ancianos, ciegos, madres recientes, que hacen de su imposibilidad del trabajo asalariado un argumento para pedir ayuda, artistas callejeros, etc.
} 
pero por falta de subsidio cerrarlas en pocas semanas, en el mercado municipal podían o no tirar comida a la basura. Así la disponibilidad estaba siempre actualizándose, con el riesgo de ser insuficiente o sobrante, y esto modificaba los circuitos llegando a veces a cubrir el objetivo en poco tiempo o en su defecto a recorrer más cuadras de las esperadas, tocar más puertas de las previstas, pedir más ayuda que de costumbre.

En la obtención de alimentos las personas acuden a situaciones como la compra diferencial, las instituciones de ayuda, los grupos de ayuda y la caridad personal. Y en estos cuatro casos pudimos ver operar la lástima y el "portarse bien" por parte de las personas sin hogar buscando reacciones morales de caridad y simpatía respectivamente por parte de los ciudadanos. En estas estrategias y reacciones morales se subyacen las tres características mencionadas al principio del artículo de Salta como ciudad intermedia: una referencia al renombre, una fuerte ética cristiana, y un arbitraje en la implementación de políticas. Seguiremos con la obtención de dinero (ya dejamos el alimento), pero debe tenerse en cuenta que también en esta obtención, las acciones y reacciones morales se deben a las características que posee Salta como ciudad de escala media.

\section{Fuentes de los deseos: robarse unas monedas}

Así como existían diferentes fuentes para conseguir alimento, existían diferentes fuentes para obtener dinero, y del mismo modo nadie hacía uso exclusivo de una sola fuente, sino de varias de ellas en complementariedad. Del mismo modo, solo trabajaremos dos situaciones: la práctica del pedir y el robo directo.

Comenzando, nos parece pertinente la reflexión de Libia Barajas sobre la práctica del pedir o lo que despectivamente se llama mendicidad (Barajas, 2012). En esta práctica, es el actuante quien solicitaba caridad, es quien pone sobre la mesa sus dolencias, sus impedimentos físicos, aprovechaba positivamente su estigma, buscando despertar en el otro el sentimiento de caridad, o en última instancia de miedo (Goffman, 2012).

Don Daniel, un salteño del interior de la provincia, quien después de vivir años en la ciudad de Córdoba acudiendo a centros de rehabilitación para alcohólicos y hospederías de ayuda prefirió volver a Salta, nos contaba mientras sostenía con la mano 
derecha un tetrabrik de vino tinto y hacía muecas ilustrativas con la izquierda "yo no robo, yo pido" recalcando que siempre "hay que ser cordial, respetuoso, y amable" con aquellos a quienes se está pidiendo, haciendo de él una persona merecedora de caridad. Por su cuenta San Juan también pedía "monedas" a los transeúntes que pasaban por la calle donde dormía, agradeciendo siempre el buen gesto con un "gracias, que Dios lo bendiga" a veces tan despacio que el donante no lograba escucharlo. Tenía un problema en su espalda que le impedía caminar erguido o dormir de espaldas, y a pesar de que siempre caminaba despacio y un poco encorvado, al momento de pedir "monedas", como él decía, siempre se encorvaba lo suficiente para que fuera evidente que lo hacía por dolor.

Otra forma de practicar el pedir se basaba en el temor, Toro era el que más eficacia tenía para conseguir dinero y "puchos", cigarrillos industriales, pero a diferencia de los demás no apelaba a su condición para ser merecedor de caridad, sino a la amenaza que causaba en el transeúnte salteño. Él sabía que su estado de ebriedad, su fachada, su voz y su comportamiento corporal proyectaban una imagen peligrosa, que producía susto, amenaza más que lástima. Por tanto, se acercaba a todos los transeúntes que tuvieran la suerte de caminar cerca de él interviniendo su camino, diciendo siempre la misma oración “ ¿no tendrás unas monedas?” o en caso que fuera un hombre joven “amigo, ¿no tendrás un pucho pa' convidarme?”. Generalmente la respuesta siempre era positiva. Los motivos de éxito oscilaban entre: no contradecir a alguien que "está borracho... es peligroso" como nos decía un hombre ya adulto que le facilitó diez pesos, y para "sacármelo de encima" en palabras de una joven que sólo le dio dos pesos. Así, este interventor del deambular urbano lograba su cometido con un éxito hasta ahora no superado.

A veces, la práctica del pedir no suponía una petición verbal, sino más bien corporal, es sabido el gesto de la mano extendida con la palma abierta hacia el cielo esperando algo que cayera de él o de otras manos más afortunadas. Pero además, existían otras prácticas corporales como la del Mudo: él "molestaba”. En palabra de los taxistas que lo cuidaban, este adulto "molestaba" a los pasajeros de los mismos, de manera tal que "jodía" hasta conseguir un poco de comida ya fuera por parte de los mismos pasajeros, los taxistas, o porque casualmente lo conseguía por otro medio. Esto hacía que los taxistas siempre tuvieran un poco de comida guardada para cuando el 
Mudo "se pusiera a joder", evidenciando que él no era "tonto, es vivo, se da cuenta de las cosas", y apelaba a la molestia, a una presencia física incomoda hasta conseguir un plato.

Tanto San Luis, don Daniel, Toro y el Mudo, realizaban actuaciones, puestas en escena. Hacían de su fachada, de sus estigmas, una ventaja ya fuera para ser merecedores de caridad, o personajes merecedores de temor o presencia molesta, lo suficiente para lograr su cometido, en este caso conseguir comida o dinero.

Hasta ahora expusimos estrategias de conseguir dinero mediante actividades no condenadas, pero algunos de estos adultos también apelaban al robo o a la reventa de objetos robados para conseguir efectivo (Snow y Anderson, 1993). Don Figueroa, un señor de cincuenta años que dormía en las puertas del cementerio de la ciudad, con la ayuda de sus amigos, entraba a la cabina de las vendedoras de flores del cementerio para arrebatarles bienes potencialmente vendibles como un equipo de música u otro por el estilo. Lejos del cementerio, don Pedro y el Chacarero, durante un tiempo compraban celulares "usados, encontrados", para revenderlos dejándole un margen de ganancia. Ellos no los robaban de manera directa pero si participaban de la venta, aunque don Pedro sostenía que no sabían de donde provenían, sino sólo los compraban y vendían, lo cual "no es nada ilegal", mientras a Chacarero le preocupaba menos quedar bien frente a nosotros. El Chino y Lucas, unos amigos del grupo pregonerito que dormían cerca del cerro que delimita la ciudad, en el afán de conseguir dinero para comprar más de la sustancia que tanto les gustaba se permitían robar a aquellos transeúntes vulnerables, sobre todo objetos de fácil reventa como celulares o en el mejor de los casos directamente dinero. "Hicimos una de las nuestras" nos decían, para referirse a aquella apropiación de bienes privados que se consideraba socialmente incorrecta.

En correspondencia por la práctica del pedir que realizaba Toro, estas persona apelan a la amenaza, para así infringir miedo y hacer el robo más sencillo, aprovechaban su fachada, su expresión corporal, su voz, su aliento, su estado de ebriedad para asumir el papel de ladrones urbanos ${ }^{7}$.

\footnotetext{
${ }^{7}$ Dejamos fuera de la reflexión aquellos robos por descuido, ya que aquí la estrategia no busca una reacción moral por parte del ciudadano, de hecho es mejor si este nunca se da cuenta del robo, quizás ya llegado a su casa, aquí se aprovecharía la situación de distracción pero merecería una reflexión separada a este análisis presentado.
} 
Entonces, repasemos para no perder el hilo de la exposición: existían situaciones donde los adultos que viven en las calles pueden obtener alimento como dinero. La forma de conseguirlos es mediante estrategias de supervivencia, donde se aprovechan estas situaciones como la compra diferencial, las instituciones de ayuda, los grupos de ayuda, la caridad personal, la práctica del pedir y el robo.

Estas interacciones estrategias apelaban, al parecer, a tres formas morales de relacionarse: el "portarse bien" como acción amistosa, la lástima, y la amenaza. Estas formas buscan la reacción de los ciudadanos que ante el "portarse bien" pueden establecer simpatía, ante la lástima reaccionan con la caridad, y frente a la amenaza, aparece el temor. Esta moralidad está presente en las distintas situaciones y sus distintas formas de acción y reacción. En términos esquemático sería algo así:

\begin{tabular}{|c|c|c|c|c|}
\hline Situación & Reacción Moral $\rightarrow$ & Simpatía & Caridad & Temor \\
\hline Compra Diferencial & & $\checkmark$ & $\mathrm{X}$ & $\mathrm{X}$ \\
\hline Institución de ayuda & & $\sqrt{ }$ & $\checkmark$ & $\mathrm{X}$ \\
\hline Grupos de Ayuda & & $\checkmark$ & $\checkmark$ & $\mathrm{X}$ \\
\hline Caridad Personal & & $\mathrm{X}$ & $\sqrt{ }$ & $\mathrm{X}$ \\
\hline Practica del Pedir & & $\mathrm{X}$ & $\sqrt{ }$ & $\checkmark$ \\
\hline Robo & & $\mathrm{X}$ & $\mathrm{X}$ & $\checkmark$ \\
\hline
\end{tabular}

Cuadro 1: Las situaciones y la reacción moral que provocan.

Aquí puede verse más claramente la lógica de la acción y la reacción moral, difícilmente uno intentará buscar caridad a una ONG amenazándola, o recibirá una caridad casi fortuita de una amistad, o intentará robar apelando a la lástima de su víctima. Aunque este cuadro tienda obviar lo investigado, cabe recordar que la segunda parte de la propuesta es sostener que estas estrategias y reacciones morales se dan en la moral de una ciudad de escala media con características propias. 


\section{Reacciones morales: simpatía, caridad, temor}

La simpatía puede efectuarse porque tanto las personas en situación de calle como los ciudadanos comparten el mismo lugar, una ciudad de renombre donde no prevalece el anonimato sino una relación de reconocimiento continuo en una copresencia de los espacios, haciendo así más factible establecer una relación amistosa permanente, es quizás por esto que en los trabajos realizados en Buenos Aires, Rosario y otras grandes ciudades no hicieron tanto énfasis en la copresencia y el renombre, sino en las políticas públicas y la forma en como las personas aprovechan o resisten frente a ellas.

En el mismo sentido, la caridad puede ser operatibizable donde la humanidad establezca o busque razones, como bien lo enuncia Didier Fassin (Fassin, 2016) pero en una ciudad con una ética cristiana tan presente, la caridad toma una forma de militancia estacional. No es casualidad que el protagonismo de la ayuda lo tomen las instituciones y grupos de ayuda, en su gran mayoría religiosos (Cáritas, Manos Abiertas, Convento, Iglesia San Alfonso, Colegio Sagrado Corazón de Jesús, Grupo Juvenil Adventista, Iglesia del Reino de Dios, Universidad Católica, etc.). De hecho sólo un grupo de ayuda no era abiertamente religioso (Fundación Si) que curiosamente tiene su sede en Buenos Aires y lo trajeron a Salta a expandir la ayuda. En el mismo sentido, aunque sólo podamos inferir es probable que la mayoría de los vecinos y transeúntes que ayuden esporádicamente a estas personas sientan el peso cristiano en su moral o al menos el de ser "buenas personas".

En correspondencia a lo sostenido, el protagonismo no solo lo llevan los grupos e instituciones de ayuda por su ferviente servicio, sino por la ausencia de políticas públicas, que en su arbitrariedad no consideran el sinhogarismo como un problema salvo aquellas excepciones que salgan en los medios locales. A diferencia de las investigaciones en Buenos Aires, Rosario y Rio de Janeiro, en Salta no existe una secretaria, un departamento, o un ministerio que se ocupe de las personas sin vivienda, salvo quizás una reubicación de las personas en invierno llevándolas en patrulla a una secretaria de policía lejos del centro sobre todo para que no mueran en el centro de la ciudad, tomando en cuenta que coincide con la temporada de turismo europeo de invierno, no obstante esta reubicación humana la comenzó un grupo civil que luego 
solicitó ayuda a la policía de la provincia. Entonces, las personas sólo están contempladas dentro de la Cooperadora Asistencial, organismo municipal de dudosa transparencia que se ocupa de situaciones "urgentes" (comedores, viviendas inundadas, quemadas, ancianos solos, etc.) considerando el problema como emergencia habitacional. No obstante, el esquema que aparenta coherencia en la práctica no invierte ni dinero ni tiempo para ningún problema eventual, salvo aquellos que por distintos motivos salieron en los medios. Esta ausencia del Estado, genera un imaginario sobre la población de extrema vulnerabilidad sobre estas personas, quienes son vistas desamparadas, sin poseer derechos.

Esta ausencia de ciudadanía genera una responsabilidad sobre el ciudadano caritativo quien se siente en la obligación de ayudar, ya que "si no los ayudamos nosotros ¿quién lo hará?" como nos decía una de las coordinadoras de los grupos de ayuda, que durante dos años salieron a repartir comida los viernes por la noche.

Así, el componente del renombre, la ética cristiana y la arbitrariedad de las políticas, generan las condiciones para que la situación se defina de tal manera que las personas puedan emplear las reacciones morales a su favor.

Finalmente, el temor también se expresa en este contexto de ciudad no metropolitana, en ningún caso vimos necesaria un arma blanca o de fuego sino más bien la mera presencia y una puesta en escena, aprovechando ciertos símbolos como la oscuridad, el silencio, la fachada, la puesta corporal y ciertas cuadras y espacios verdes que en el imaginario urbano salteño son consideradas peligrosas. En un artículo anterior lo denominamos zonas de azar en oposición a las zonas de vigilancia dentro de la morfología salteña (Fernández, 2016). La situación de robo tampoco implica una zona liberada que supone un crimen organizado, sino espacios de aprovechamiento de la oportunidad, incluso Chino y Lucas estaban más cerca del azar que de programar sus asaltos, o Toro, quien encaraba a quien tuviera la suerte de pasar por ahí. No obstante no hay que olvidar que en Salta sí existe delito, crimen relativamente organizado, venta de drogas, zonas liberadas, etc., pero lo que respecta a la situación de amenaza que aprovechan estos actores no supera la puesta en escena y algún que otro forcejeo. 


\section{Palabras finales}

Pudimos ver cómo las personas en situación de calle en la actual ciudad de Salta emplean estrategias de supervivencia para poder cubrir sus necesidades básicas. Parte de estas necesidades refiere a la obtención de comida y de dinero.

Como lo presentamos, estas obtenciones se dan en interacciones que podríamos definir como estratégicas, pero no de manera azarosa o individual, sino que están delimitadas por la moral que acontece en el lugar, en este caso la ciudad de Salta, que le da forma a estas interacciones.

De este modo, esta moral presenta ciertas características de la cuales no es necesario distinguir que existe una prevalencia del renombre, o sea que las relaciones urbanas no son meramente anónimas sino que hay un reconocimiento a través de la copresencia cotidiana de los actores, que hace que importante la fama, posible por la escala de la ciudad, de poco peso en los otros estudios de personas sin hogar realizadas en grandes metrópolis.

En el mismo sentido también es menester mencionar la fuerte ética cristiana que envuelve todas las veredas salteñas, distinguible por el protagonismo que toman las iglesias y religiosidad al conformarse grupos de ayuda, al ser instituciones que brindan desayunos y almuerzos, la constante caridad de los transeúntes, etc. que opaca la participación del Estado, que se limita a acciones de poca monta y su presencia policial.

En el mismo sentido, al existir una arbitrariedad personal en la implementación de políticas públicas, estas personas no son contempladas como sujetos de derecho, lo que promueve aún más la caridad ciudadana, así, las políticas públicas no son una opción de acción ni para los ciudadanos ni para las personas sin hogar.

Como estrategia, estas personas invocan la moral que comparten con el resto de los habitantes de la ciudad. En las situaciones de obtención de recursos, se "portan bien” para así establecer una relación simpática, apelan a la lástima para producir efectos de caridad, y finalmente realizan amenazas para provocar temor. Tanto estas acciones morales como sus respectivas reacciones operan en una moral de fondo posible en una ciudad media como Salta. En este sentido, no sería infundado suponer que en ciudades de iguales características se produzcan similares acciones y reacciones. 


\section{Referencias}

ANDERSON, Neil. Thehobo. TheSociology of the Homeless man. Chicago Press. Chicago. 1923.

AUGE, Marc. Los no lugares. Espacios del anonimato. Gedisa. España. 2000.

BARAJAS MARISCAL, Libia Elena "Discurso de mano en mano (un estudio de caso de la indigencia en la ciudad de México" en Revista Discurso y Sociedad No 6. México DF. 2012.

BARREAT MONTERO, Yareani "Estudio psicosocial de la indigencia en Mérida" en Revista Medula $\mathrm{N}^{\mathrm{0}}$ 1. Vol 16. Centro de investigaciones Psicológicas. Facultad de Medicina. Universidad de Los Andes. Mérida. 2007.

BIAGGIO, Mariana. "Entre la penalización y la asistencia: la construcción de sujetos 'merecedores' de políticas públicas destinadas a la atención de la 'emergencia habitacional' en la ciudad de Buenos Aires" en Revista Margen 57. Buenos Aires. 2010. BIAGGIO, Mariana. "Linyera, ser o no ser: normas, códigos y estrategias de supervivencia de los hombres de la calle" en Actas VIII Congreso Argentino de Antropología Social. Universidad Nacional de Salta. 2006.

BIAGGIO, Mariana. "Salir de la calle: una aproximación etnográfica a un proyecto de revinculación social para personas en situación de calle en la Ciudad de Buenos Aires. 2011.

BIOGGI, Silvia y GALVAN, Nora. "Ciudad media, ciudad intermedia: ¿ni chica ni limonada?" en Ciudades vividas. Sistemas e imaginarios de ciudades medias bonaerenses. GRAVANO Ariel, et at. Editorial Café de las ciudades. Buenos Aires. 2016

BOLSTANSKI, Luc. Onjustification. Economies of worth. Princeton UniversityPress. TheUnitedStates of America. 2006.

BUFARINI, Mariel "Transformaciones en el espacio urbano. Las personas sin hogar y los usos del espacio urbano público" en Revista de la Escuela de Antropología. Facultad de Humanidades y Artes. UNR. Rosario. 2008.

BUFARINI, Mariel "Vivir en el centro de la ciudad. Análisis de los usos del espacio público de las personas sin hogar" en VII Reunión de Antropología del Mercosur. Porto Alegre. Brasil. 2007.

BUFARINI, Mariel "Vivir en el espacio Público: consideraciones sobre las políticas de control urbano" en Revista Nómadas № 37. Octubre. Universidad Central. Colombia. 2012.

CABRERA CABRERA, Pedro José. Huéspedes del Aire. Sociología de las personas sin hogar en Madrid. Madrid. Editorial Universidad Pontificia Comillas. 1998.

FASSIN, Didier. La razón humanitaria. Una historia moral del tiempo presente. Prometeo libros. 2016.

FERNANDEZ, Luis Alfredo. "Lógicas de ocupación espacial de las personas en situación de calle en la ciudad de Salta" en Revista Nuestro NOA № 6. Junio. Jujuy. 2016.

FERRÉ ESPINOZA, Francisca Javiera. Habitar la calle: del espacio al lugar. El caso de adultos en situación de calle. Universidad Academia de Humanismo Cristiano. Santiago de Chile. 2011.

FLORES KLARIK, Mónica. La construcción de Salta "La Linda”. Aportes para una Antropología del Turismo. Universidad nacional de Salta. Salta. 2001. 
GOFFMAN, Erving. StrategicInteraction. University of Pennsylvania Press. Philadelphia.1971.

GOFFMAN, Erving. Estigma. La identidad deteriorada. Editorial Amorrortu. Buenos Aires. 2012.

GRAEFF, Lois "Corpos precários, Desrepeito e Autoestima: o caso de Moradores de Rua de Paris-Fr.” Em Psicologia USP No 23. São Paulo. 2012.

GRAVANO, Ariel. Antropologia de lo urbano. Editorial Unicen. 2013

HANNERZ, Ulf. Exploración de la ciudad. Hacia una antropología urbana. Fondo de Cultura Económica. México. 1993.

JARDIM FRAZAO, Theresa Christina. O morador de rua e a invisibilidade do sujeito no discurso jornalístico. Universidad de Brasilia. Brasilia, 2010.

LOMNITZ, Larissa Adler de ¿Cómo viven los marginados? Editorial Siglo XXI. México. 1998.

MARPSAT, Maryse, et FIRDION, Jean-Marie. La Rue et le Foyer. Une recherche sur les sansdomicile et les mal-logésdans les années 1990, EMED-PUF, coll. « Travaux et documents ».Paris. 2000.

MARPSAT, Maryse. Estadisticas das pessoassem domicilio naFrança: Historias, métodos e resultados. Instituto Nacional de estadísticas e de EstudosEconomicos. Paris. 2012.

NECTOUX, Marcia "Os desafios dos processos de monitoramento e avilaçao nos serviçios de acolhimento à populaçao adulta em situaçao de rua na gestao pública da política de assistencia social" em SCHUCH, Patrice. A rua em movimento, FASC. Porto Alegre. 2012

PALLERES, Griselda. "Derecho a la ciudad: personas sin hogar en la ciudad de Buenos Aires" en Dimensiones del habitad popular latinoamericano. Flacso. Ecuador. 2012.

PALLERES, Griselda. "Resignificación socio espacial y construcción de subjetividad. Personas sin hogar en la Ciudad de Buenos Aires". En Revista CUHSO. Volumen 19, numero 1. Chile. 2010.

PALLERES, Griselda. Conjugando el presente. Personas sin hogar en la ciudad de Buenos Aires. Universidad de Buenos Aires. Buenos Aires. 2004.

PARK, Erza. WorldTomorrow. Chicago Press. Chicago. 1923.

PEREIRA, Aline Valadão Vieira Gualda. A Indumentária da População de Rua. Repensando Paradigmas. Editorial UNESA. Rio de Janeiro. 2003.

PICHON, Pascale. Vivre sans domicile fixe: l'épreuve de l'habitat précaire. Revistecomunicatiosn. Paris. 2002.

ROSA, Paula Cecilia "Percepciones de los coordinadores de programas sociales destinados a los habitantes de la calle en la ciudad de Buenos Aires" en Revista Debate Público. Reflexiones de trabajo social. № 5, año 3.2013

ROSA, Paula Cecilia "Pobreza urbana y desigualdad: la asistencia habitacional a personas en situación de calle en la ciudad de Buenos Aires". En Dimensiones del habitad popular latinoamericano. Flacso. Quito. 2012.

SCHUCH, Patrice. et al. A Rua em movimento: debates acerca da população adulta em situação de rua na cidade de Porto Alegre. Fundação de AssistênciaSocil e Cidadania da Prefeitura Municipal de Porto Ale. 2012.

SIMMEL, George. Filosofía del dinero. Instituto de estudios políticos. España.1977.

SILVA, Ana y BOGGI, Silvia. "Estudios sobre imaginarios de ciudades medias" en Ciudades vividas. Sistemas e imaginarios de ciudades medias bonaerenses. GRAVANO Ariel, et at. Editorial Café de las ciudades. Buenos Aires. 2016. 
SNOW, David y ANDERSON Leon. Down on their Luck. A study of homeless street people. University of California Press. California. 1993.

SNOW, David, et at. The Mythofpervasive mental illnessamongtheHomeless. UniversidadofCalifornia Press. California. 1986.

THOMAS, William. La definición de situación. Cuadernos de Información y comunicación. México. 2005.

TURNES, Brawn; y TURNES, James. Building Community: a third word case book. An summary of the habitat international coalition non-governmental organization's project for the international year of shelter for homeless, 1987. BuildingCommunityBooks. London. 1988.

WEASON NUÑEZ, MacarenaAlejandra.Personas en situación de calle: reconocimiento e identidad en contextodeexclusión social. Universidad Alberto Hurtado. Santiago de Chile. 2006.

Recebido em: 15/10/2017.

Aprovado em: 15/11/2017. 